\title{
TANGGUNG JAWAB PERAWAT GIGI TERHADAP TINDAKAN PELAYANAN KESEHATAN GIGI YANG SESUAI DAN TIDAK SESUAI KOMPETENSI
}

\author{
Prasko $^{1 凶}$, Salikun $^{2}$, Iman Supardan ${ }^{3}$
}

\begin{abstract}
ABSTRAK
Kewenangan yang dimiliki oleh seorang perawat gigi untuk melaksanakan tugas pelayanannya adalah kewenangan hukum (rechtsbevoegheid). Atas dasar kewenangan inilah, seorang tenaga kesehatan berhak melakukan pengobatan sesuai dengan kompetensinya. Bila persyaratan administratif untuk melaksanakan profesinya telah dipenuhi, maka perawat gigi sebagai pengemban profesi telah memperoleh kewenangan profesional dalam menjalankan pekerjaannya. Namun, bila seorang tenaga kesehatan melakukan pekerjaan tanpa kewenangan, dapat dianggap melanggar salah satu standar profesi tenaga kesehatan. Tujuan penelitian ini adalah mengetahui pelaksanaan tanggung jawab Perawat Gigi terhadap tindakan pelayanan kesehatan gigi di Puskesmas Bergas, Puskesmas Duren dan Puskesmas Suruh di Kabupaten Semarang.

Jenis penelitian ini adalah penelitian deskriptif yang bertujuan menggambarkan secara sistematik dan akurat fakta dan karakteristik mengenai populasi atau mengenai bidang tertentu. Penelitian ini berusaha menggambarkan situasi atau kejadian. Instrumen yang dipergunakan adalah dengan kuesioner.

Dari hasil penelitian yang dilakukan peneliti dilapangan terhadap Perawat Gigi di Puskesmas Duren, Puskesmas Suruh dan Puskesmas Bergas di Kabupaten Semarang dengan cara wawancara dapat diketahui dan didapatkan hasil bahwa sebagian besar Perawat Gigi yang bekerja di puskesmas telah melaksanakan tanggung jawab pekerjaannya dengan baik sesuai dengan kompetensi Perawat Gigi dan sudah sesuai dengan peraturan perundang-undangan yang mengatur Perawat Gigi. Tetapi didapatkan juga hasil penelitian bahwa sebagian kecil Perawat Gigi yang melakukan tindakan diluar kompetensi yang diatur dalam perundang-undangan yang mengatur Perawat gigi.
\end{abstract}

Kata kunci : Tanggung jawab perawat gigi, pelayanan kesehatan gigi

\begin{abstract}
Authority possessed by a dental nurse to perform ministerial duties is the legal authority (rechtsbevoegheid). On the basis of this authority, a health worker is entitled to treatment in accordance with their competence. When the administrative requirements to carry out the profession have been met, then the dental nurse as a profession carrier has obtained the professional authority in the work. However, if a health worker do the job without authority, may be considered to violate one of the professional standards of health workers. The purpose of this study was to determine the responsibility of Dental Nurses implementation of the actions of dental health services in Bergas PHC, Duren PHC and Suruh PHC in district of Semarang.

This research is a descriptive study that aims to describe systematically and accurately the facts and characteristics of the population or about a particular field. This study sought to describe a situation or event. The instrument used was the questionnaire.

From the results of the study conducted by researchers in the field of the Dental Nurses at Duren PHC, Duren PHC and Suruh PHC in district of Semarang by interview can be seen and showed that the majority of Dental Nurses who work in clinics have been carrying out job responsibilities properly in accordance with the competence of Nurses teeth and is in conformity with the laws and regulations governing dental Nurses. But also the results obtained that a small portion Dental Nurses who perform actions beyond the competence stipulated in the legislation governing the dental nurse.
\end{abstract}

Keywords : Responsibilities of Dental Nurses, Dental Health Care Measures

\footnotetext{
$\overline{1,2,3)}$ Dosen Jurusan Keperawatan Gigi Poltekkes Kemenkes Semarang

凶: praskoabdullah@yahoo.co.id
} 


\section{PENDAHULUAN}

Undang-Undang Dasar 1945 Pasal $28 \mathrm{H}$ (1) menjelaskan bahwa setiap orang berhak hidup sejahtera lahir dan batin, bertempat tinggal, dan mendapatkan lingkungan hidup yang baik dan sehat serta berhak memperoleh pelayanan kesehatan. Dijelaskan juga pada Pasal 34 (3) menjelaskan bahwa negara bertanggung jawab atas penyediaan fasilitas pelayanan kesehatan dan fasilitas pelayanan umum yang layak.

Kesehatan adalah hak dasar setiap individu dan semua warga negara berhak mendapatkan pelayanan kesehatan yang memadai. Dalam Undang-Undang Nomor 40 tahun 2004 tentang Sistem Jaminan Sosial Nasional mengamanatkan untuk memberikan perlindungan bagi fakir miskin, anak, dan orang terlantar serta orang tidak mampu yang pembiayaan kesehatannya di jamin oleh pemerintah.

Pelayanan kesehatan merupakan merupakan penyelenggaraan upaya kesehatan dalam rangkaian pemeliharaan dan peningkatan derajat kesehatan diri. Bentuk pelayanan kesehatan ini tidak hanya difokuskan pada pelayanan kesehatan individu tetapi juga pada pelayanan kesehatan masyarakat. Pelaksanaan pelayanan kesehatan ini tentunya ditunjang oleh sumber daya kesehatan yang dapat berupa segala bentuk dana, tenaga, perbekalan kesehatan, sediaan farmasi dan alat kesehatan serta fasilitas pelayanan kesehatan dan teknologi yang dimanfaatkan untuk penyelenggaraan upaya kesehatan.

Seluruh kegiatan pelayanan kesehatan yang dilakukan oleh sumber daya kesehatan selalu diatur oleh kaidah-kaidah yang dikumpulkan dalam peraturan-peraturan yang mengikat. Kaidah-kaidah hukum ini sangatlah diperlukan dalam mengatur hubungan-hubungan hukum yang terjadi didalam pelayanan kesehatan. Hubungan antar manusia yang terjadi didalam pelayanan kesehatan adalah interaksi sosial yang berpedoman pada norma/kaidah untuk mewujudkan nilai-nilai dasar yang harus tercipta dalam upaya pelayanan kesehatan. Nilai-nilai dasar ini perlu diwujudkan agar di dalam interaksi sosial tersebut terjadi suatu harmoni dan mencegah terjadinya pertentangan/konflik.

Selain menjalankan fungsi

keperawatan, pemerintah Indonesia mengharapkan hal-hal tertentu dari seorang perawat. Perawat harus loyal terhadap negara sebagaimana mereka loyal kepada profesi dan masyarakat yang dilayaninya. Sebagai pelaksana kebijakan kesehatan nasional, perawat harus ikut berperan dalam upaya meningkatkan derajat kesehatan bangsa, meningkatkan mutu pelayanan kesehatan, memelihara kesejahteraan masyarakat, hingga ikut memberikan sumbangan dalam mewujudkan tujuan WHO (World Health Organization).

Pelaksanaan pelayanan asuhan kesehatan gigi dan mulut berdasarkan Keputusan Direktur Jenderal Pelayanan Medik (1995) dinyatakan bahwa pelaksana pelayanan asuhan kesehatan gigi dan mulut adalah perawat gigi dan dilaksanakan di semua unit pelayanan kesehatan gigi dan mulut di Puskesmas dengan sasaran utama kepada kelompok masyarakat yang rentan terhadap penyakit gigi dan mulut yaitu kelompok anak prasekolah, anak sekolah dasar dan ibu hamil.

Kewenangan yang dimiliki oleh seorang perawat gigi untuk melaksanakan tugas pelayanannya adalah kewenangan hukum (rechtsbevoegheid). Atas dasar kewenangan inilah, seorang tenaga kesehatan berhak melakukan pengobatan sesuai dengan kompetensinya. Bila persyaratan administratif untuk melaksanakan profesinya telah dipenuhi, maka perawat gigi sebagai pengemban profesi telah memperoleh kewenangan profesional dalam menjalankan pekerjaannya. Namun, bila seorang tenaga kesehatan melakukan pekerjaan tanpa kewenangan, dapat dianggap melanggar salah satu standar profesi tenaga kesehatan.

Tindakan atau perbuatan tenaga kesehatan sebagai subyek hukum dalam 
pergaulan masyarakat, dapat dibedakan antara tindakannya sehari-hari yang tidak berkaitan dengan profesi, dan tindakan yang berkaitan dengan pelaksanaan profesi. Begitu pula dalam tanggung jawab hukum seorang tenaga kesehatan, dapat tidak berkaitan dengan profesi, dan dapat pula merupakan tanggung jawab hukum yang berkaitan dengan pelaksanaan profesinya.

Perbuatan tenaga kesehatan yang tidak berkaitan dengan pelaksanaan profesi dengan kata lain Perawat Gigi sebagai warga negara yang dapat menimbulkan tanggung jawab hukum antara lain : menikah, melakukan perjanjian jual beli, membuat wasiat, mencuri, menipu, menganiaya dan lain sebagainya. Perbuatan tenaga kesehatan yang tidak berkaitan dengan pelaksanaan profesinya ini, pada umumnya juga bisa dilakukan oleh setiap orang yang bukan tenaga kesehatan.

Dalam menjalankan kewajiban hukumnya, diperlukan adanya ketaatan dan kesungguhan dari tenaga kesehatan tersebut dalam melaksanakan kewajiban sebagai pengemban profesi. Kesadaran hukum yang dimiliki tenaga kesehatan harus berperan dalam diri tenaga kesehatan tersebut untuk bisa mengendalikan dirinya sehingga tidak melakukan kesalahan profesi, agar terhindar dari sanksi yang diberikan oleh hukum.

\section{METODE PENELITIAN}

Jenis penelitian ini adalah penelitian deskriptif yang bertujuan menggambarkan secara sistematik dan akurat fakta dan karakteristik mengenai populasi atau mengenai bidang tertentu. Penelitian ini berusaha menggambarkan situasi atau kejadian. Data yang dikumpulkan sematamata bersifat deskriptif sehingga tidak bermaksud mencari penjelasan, menguji hipotesis, membuat prediksi, maupun mempelajari implikasi.

Pengumpulan data dalam penelitian ini menggunakan teknik wawancara yang dilakukan peneliti kepada Perawat Gigi
Puskesmas Bergas, Puskesmas Duren dan Puskesmas Suruh Kabupaten Semarang.

Metode analisis data dalam penelitian ini adalah analisis kualitatif. Menurut Miles dan Huberman (1984), dalam analisis data kualitatif dilakukan secara interaktif dan berlangsung secara terus menerus sampai tuntas, sehingga datanya sudah jenuh.

\section{HASIL DAN PEMBAHASAN}

Tabel 1. Hasil kuesioner tindakan pencabutan gigi sesuai kompetensi

\begin{tabular}{ccccc}
\hline \multirow{2}{*}{ No } & \multirow{2}{*}{$\begin{array}{c}\text { Nama } \\
\text { Puskesmas }\end{array}$} & \multicolumn{2}{c}{ Jumlah Perawat } & \\
& Ya & Tidak & Keterangan \\
\hline 1 & Duren & 2 & - & $\begin{array}{c}\text { Sudah Menjadi } \\
\text { Kewajiban }\end{array}$ \\
\hline 2 & Suruh & 2 & - & $\begin{array}{c}\text { Sudah Menjadi } \\
\text { Kewajiban }\end{array}$ \\
\hline 3 & Bergas & 2 & - & $\begin{array}{c}\text { Sudah Menjadi } \\
\text { Kewajiban }\end{array}$ \\
\hline & Jumlah & 6 & - & \\
\hline
\end{tabular}

Dari tabel 1 diatas dapat dilihat bahwa pada tindakan pencabutan gigi sesuai kompetensi pada Puskesmas Duren, Puskesmas Suruh dan Puskesmas Bergas di Kabupaten Semarang seluruh Perawat Gigi melakukan tindakan pencabutan gigi sesuai kompetensinya. Alasan yang diutarakan bahwa tindakan pencabutan sesuai kompetensi merupakan pekerjaan rutin yang setiap hari dikerjakannya dan sudah menjadi kewajibannya dalam bekeja sebagai perawat gigi.

Tabel 2. Hasil kuesioner tindakan pencabutan gigi bukan kompetensi

\begin{tabular}{ccccc}
\hline No & \multirow{2}{*}{$\begin{array}{c}\text { Jama } \\
\text { Puskesmas }\end{array}$} & \multicolumn{2}{c}{ Gigi } & Keterangan \\
& Ya & Tidak & \\
\hline 1 & Duren & 2 & - & $\begin{array}{c}\text { Ada tugas limpah } \\
\text { dari Dokter Gigi }\end{array}$ \\
\hline 2 & Suruh & 2 & - & $\begin{array}{c}\text { Ada tugas limpah } \\
\text { dari Dokter Gigi }\end{array}$ \\
\hline 3 & Bergas & 2 & - & $\begin{array}{c}\text { Ada tugas limpah } \\
\text { dari Dokter Gigi }\end{array}$ \\
\hline \multicolumn{2}{c}{ Jumlah } & 6 & - & \\
\hline
\end{tabular}


Dari tabel 2 diatas dapat dilihat bahwa pada tindakan pencabutan gigi yang bukan kompetensi pada Puskesmas Duren, Puskesmas Suruh dan Puskesmas Bergas di Kabupaten Semarang seluruh Perawat Gigi melakukan juga tindakan pencabutan gigi yang bukan kompetensinya. Alasan yang diutarakan bahwa tindakan pencabutan yang bukan kompetensinya dilakukan dengan adanya tugas limpah dari Dokter Gigi dan juga merrupakan pekerjaan rutin yang setiap hari dikerjakannya.

Tabel 3. Hasil kuesioner tindakan penambalan gigi sesuai kompetensi

\begin{tabular}{ccccc}
\hline No & \multirow{2}{*}{ Nama } & \multicolumn{3}{c}{ Jumlah Perawat } \\
Puskesmas & \multicolumn{2}{c}{ Gigi } & Keterangan \\
& Ya & Tidak & \\
\hline 1 & Duren & 2 & - & $\begin{array}{c}\text { Sudah Menjadi } \\
\text { Kewajiban }\end{array}$ \\
\hline 2 & Suruh & 2 & - & $\begin{array}{c}\text { Sudah Menjadi } \\
\text { Kewajiban }\end{array}$ \\
\hline 3 & Bergas & 2 & - & $\begin{array}{c}\text { Sudah Menjadi } \\
\text { Kewajiban }\end{array}$ \\
\hline & Jumlah & 6 & - & \\
\hline
\end{tabular}

Dari tabel 3 di atas dapat dilihat bahwa pada tindakan penambalan gigi sesuai kompetensi pada Puskesmas Duren, Puskesmas Suruh dan Puskesmas Bergas di Kabupaten Semarang seluruh Perawat Gigi melakukan tindakan penambalan gigi sesuai kompetensinya. Alasan yang diutarakan bahwa tindakan penambalan gigi sesuai kompetensi merupakan pekerjaan rutin yang setiap hari dikerjakannya dan sudah menjadi kewajibannya dalam bekeja sebagai perawat gigi.

Tabel 4. Hasil kuesioner tindakan penambalan gigi bukan kompetensi

\begin{tabular}{ccccc}
\hline No & \multirow{2}{*}{ Nama } & \multicolumn{2}{c}{ Jumlah Perawat } & Gigi \\
& Puskesmas & Ya & Tidak & Keterangan \\
\hline 1 & Duren & 2 & - & $\begin{array}{c}\text { Ada tugas limpah } \\
\text { dari Dokter Gigi }\end{array}$ \\
\hline 2 & Suruh & 2 & - & $\begin{array}{c}\text { Ada tugas limpah } \\
\text { dari Dokter Gigi }\end{array}$ \\
\hline 3 & Bergas & 2 & - & $\begin{array}{c}\text { Ada tugas limpah } \\
\text { dari Dokter Gigi }\end{array}$ \\
\hline Jumlah & 6 & - & \\
\hline
\end{tabular}

Dari tabel 4 diatas dapat dilihat bahwa pada tindakan penambalan gigi yang bukan kompetensi pada Puskesmas Duren, Puskesmas Suruh dan Puskesmas Bergas di Kabupaten Semarang seluruh Perawat Gigi melakukan juga tindakan penambalan gigi yang bukan kompetensinya. Alasan yang diutarakan bahwa tindakan penambalan gigi yang bukan kompetensinya dilakukan dengan adanya tugas limpah dari Dokter Gigi dan juga merupakan pekerjaan rutin yang setiap hari dikerjakannya.

Dalam pertanggungjawaban hukum seorang perawat gigi sebagai pengemban profesi harus mengerti dan memahami ketentuan-ketentuan hukum yang berlaku dalam pelaksanaan profesinya, termasuk di dalamnya tentang pemahaman hak-hak dan kewajiban dalam menjalankan profesi sebagai perawat gigi.

Tanggung jawab Perawat Gigi dalam melakukan tindakan pencabutan gigi dan penambalan gigi sesuai kompetensi sudah terlaksana dengan baik. Tindakan pencabutan sesuai kompetensi juga telah sesuai dengan Peraturan Pemerintah tentang Tenaga Kesehatan yang menyatakan setiap tenaga kesehatan dalam melakukan tugasnya berkewajiban untuk mematuhi standar profesi tenaga kesehatan, serta tidak melanggar Undang-Undang bahwa Tenaga kesehatan harus memenuhi ketentuan kode etik, standar profesi, hak pengguna pelayanan kesehatan, standar pelayanan dan standar prosedur operasional.

Dalam wawancara dikemukakan adalah tindakan pencabutan gigi dan penambalan gigi yang bukan kompotensi dilakukan oleh Perawat gigi karena terbatasnya jumlah Dokter Gigi di Puskesmas, jumlah Dokter Gigi di Puskesmas rata-rata hanya satu orang, sedangkan disisi lain banyaknya jumlah masyarakat yang datang untuk berobat gigi ke Puskesmas datang dengan keluhan berat dan rata-rata merupakan indikasi penyakit yang bukan merupakan kompetensi dari Perawat Gigi. 
Tindakan pencabutan gigi dan penambalan gigi bukan kompetensi yang dilakukan oleh Perawat Gigi juga disertai tugas limpah dari Dokter Gigi, hal ini selaras peraturan bahwa dalam menjalankan pekerjaan sebagai Perawat Gigi harus sesuai dengan pelayanan asuhan kesehatan gigi dan mulut, serta melaksanakan tindakan medik terbatas dalam bidang kedokteran gigi sesuai permintaan tertulis dari Dokter Gigi.

Standar profesi perawat gigi mengikat perawat gigi dalam memberikan pelayanan kesehatan kepada pasien. Didalamnya terkandung standar kompetensi dan unjuk kerja perawat gigi dalam melakukan tugas pelayanannya serta kode etik yang merupakan landasan dalam bekerja secara profesional. Artinya, seorang perawat gigi tidak hanya dituntut untuk memiliki kemampuan yang optimal tetapi juga memiliki cara dan sikap hidup yang terpuji baik dalam hubungannya dengan pasien, masyarakat, rekan sejawat maupun profesinya.

Dalam menjalankan profesinya, setiap perawat gigi Indonesia wajib memberikan pelayanan yang sebaik mungkin kepada individu dan masyarakat tanpa membedakan budaya, etnik, kepercayaan dan status ekonominya. Pelayanan sebaik mungkin disini adalah pelayanan yang sesuai dengan standar kompetensi dan standar profesi dimana didalamnya dituntut adanya kehati-hatian dan ketelitian dalam melaksanakan tindakan pelayanan asuhan kesehatan gigi dan mulut kepada pasien.

\section{KESIMPULAN}

1. Tanggung jawab Perawat Gigi dalam melakukan tindakan pencabutan gigi sudah sesuai kompetensi dan sudah terlaksana dengan baik. Tanggung jawab Perawat Gigi dalam melakukan tindakan pencabutan gigi bukan kompetensi dilakukan Perawat Gigi disertai tugas limpah dari Dokter Gigi.

2. Tanggung jawab Perawat Gigi dalam melakukan tindakan penambalan gigi sudah sesuai kompetensi dan sudah terlaksana dengan baik. Tanggung jawab Perawat Gigi dalam melakukan tindakan penambalan gigi bukan kompetensi dilakukan Perawat Gigi juga disertai tugas limpah dari Dokter Gigi.

\section{SARAN}

1. Meningkatkan pengetahuan dan pemahaman Perawat Gigi sebaik mungkin untuk memberikan kesadaran hukum tentang profesinya yang dilakukan oleh Puskesmas tempat bekerja, Dinas Kesehatan dan Organisasi Profesi Perawat Gigi.

2. Dinas Kesehatan terkait secara terusmenerus melakukan pengawasan terhadap tindakan pelayanan kesehatan gigi yang dilakukan oleh Perawat gigi.

\section{DAFTAR PUSTAKA}

Ashshofa, B, 2004, Metode Penelitian Hukum, Rineka Cipta, Jakarta

Azwar, S, 2004, Metode Penelitian, Pustaka Pelajar, Yogyakarta

Depkes R.I, 1995, Tata Cara Kerja Pelayanan Asuhan Kesehatan Gigi Dan Mulut Di Puskesmas, Jakarta

Isfandyarie, A, 2006, Tanggung Jawab Hukum dan Sanksi bagi Dokter, Prestasi Pustaka Publisher, Jakarta

Kepmenkes RI, Nomor 284 Tahun 2006 Tentang Standar Pelayanan Asuhan Kesehatan Gigi dan Mulut

Permenkes RI, Nomor 58 Tahun 2012 Tentang Penyelenggaraan Pekerjaan Perawat Gigi 
Rosalia, S, 2008, Perawat Puskesmas Di Antara Pengobatan Dan Perawatan, Gadjah Mada University Press, Yogyakarta

Supriadi, W.C., 2001, Hukum Kedokteran, Mandar Maju, Bandung

Undang-Undang RI, Nomor 36 Tahun 2009 Tentang Kesehatan

Undang-Undang RI, Nomor 40 Tahun 2004 Tentang Sistem Jaminan Sosial Nasional

Undang-Undang RI, Nomor 36 Tahun 2014 Tentang Tenaga Kesehatan

Tutik, T.T, dan Febriana,S, 2010, Perlindungan Hukum Bagi Pasien, Prestasi Pustaka Publisher, Jakarta 